\title{
Scintimammography with technetium-99m methoxyisobutylisonitrile: results of a prospective European multicentre trial
} \author{
A.J.W. Hilson', A. Bischof-Delaloye ${ }^{9}$ \\ 1 Department of Nuclear Medicine, University of Bonn, Germany \\ 2 Department of Nuclear Medicine, National Cancer Institute of Naples, Italy \\ ${ }^{3}$ Department of Nuclear Medicine, Centre Jean Perrin in Clermont Ferrand, France \\ ${ }^{4}$ Department of Nuclear Medicine, University Hospital of Zaragoza, Spain \\ 5 Department of Gynecology, University of Hamburg, Germany \\ 6 Department of Nuclear Medicine, Hospital St. Pierre in Bruxelles, Belgium \\ 7 Department of Nuclear Medicine, University Hospital in Liège, Belgium \\ 8 Department of Nuclear Medicine, NHS Trust Hospital in London, United Kingdom \\ 9 Department of Nuclear Medicine, University of Lausanne, Switzerland
}

H. Palmedo1, H.J. Biersack1, S. Lastoria², J. Maublant ${ }^{3}$, E. Prats ${ }^{4}$, H.E. Stegner ${ }^{5}$, P. Bourgeois ${ }^{6}$, R. Hustinx

Received 11 October and in revised form 12 December 1997

\begin{abstract}
The aim of the trial was to determine the diagnostic accuracy of scintimmammography with technetium- $99 \mathrm{~m}$ methoxyisobutylisonitrile ( ${ }^{99} \mathrm{~m}$ Tc-MIBI) in the detection of primary breast cancer and to verify its clinical usefulness. A total of 246 patients with a suspicious breast mass or positive mammogram were included in this prospective European multicentre trial. At $5 \mathrm{~min}$ and 60 min (optional) p.i. two lateral prone images were acquired for $10 \mathrm{~min}$ each; $30 \mathrm{~min}$ p.i. one anterior image was acquired for $10 \mathrm{~min}$. There were 253 lesions (195 palpable and 58 non-palpable), in respect of which histology revealed 165 cancers and 88 benign lesions. Institutional and blinded read results were correlated to core laboratory histopathology results obtained during excisional biopsy. Diagnostic accuracy for the detection of breast cancer was calculated per lesion. The overall sensitivity and specificity of blinded read scintimammography were $71 \%$ and $69 \%$, respectively. For palpable lesions, the sensitivity of blinded read and institutional read scintimammography was $83 \%$ and $91 \%$, respectively. Sensitivity was not dependent on the density of the breast tissue. Invasive ductal and invasive lobular cancers showed similar sensitivity. The sensitivity and specificity of mammography were $91 \%$ and $42 \%$, respectively, and did not depend on the tumour size. In $60 \%$ of

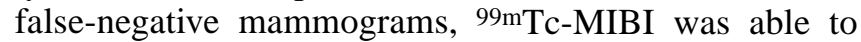
diagnose malignancy (true-positive). High-quality imag-

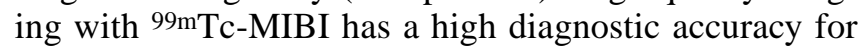
the detection of primary breast cancer. Used as a complementary method, scintimammography with $99 \mathrm{mTc}-$
\end{abstract}

Correspondence to: H. Palmedo, Department of Nuclear Medicine, University of Bonn, Sigmund-Freud-Strasse 25, D-53127 Bonn, Germany
MIBI can help to diagnose breast cancer at an earlier stage in patients with dense breasts.

Key words: Technetium-99m methoxyisobutylisonitrile Scintimammography - Breast cancer - Dense breasts Mammography

Eur J Nucl Med (1998) 25:375-385

\section{Introduction}

Breast cancer accounts for the highest proportion of cancer-related deaths among women [1,2]. Over recent decades, it has been shown that the incidence of this malignant disease has increased and is still increasing [3]; this is especially true in younger age groups. It seems possible that mortality might be reduced by therapeutic approaches as well as by efficient diagnostic methods. A significant benefit for the survival of breast cancer patients who are older than 50 years has been demonstrated using mammography as a screening method [4-6]. However, for patients younger than 50 years, a significant reduction of mortality could not be proven. Yet, it is in this patient group that major difficulties and frequent delays in the diagnosis of breast malignancies are often experienced [7]. The main reason for the diagnostic problems is dense or hyperproliferative glandular breast tissue which is typical for the premenopausal woman. Therefore, lumpy and mammographically dense breasts are frequent in this age group, and the sensitivity of palpation and mammography is significantly decreased [8]. 
Studies have shown that tumour size correlates with the frequency of axillary and distant metastases [9, 10]. For a cancer size of $1.5 \mathrm{~cm}$, the rate of axillary disease has been calculated to be about $30 \%$, whereas cancers with a size of $3 \mathrm{~cm}$ showed an increased rate of $48 \%$ [9]. Furthermore, 8 years after primary therapy of breast cancer, distant metastases occur with a probability of about $20 \%$ in the case of cancers of between 1 and $2.5 \mathrm{~cm}$ but with a probability of $40 \%$ when cancers are between 3.5 and $4 \mathrm{~cm}$ in size [11]. It has been shown that distant metastases correlate with mortality [12]. Thus, it is clear that the earlier tumours are detected, the better will be the survival rate of patients.

Recently, encouraging results have been obtained by means of nuclear breast imaging using different radiopharmaceuticals such as fluorine-18 fluordeoxyglucose, technetium-99m methoxyisobutylisonitrile (99m TcMIBI), thallium-201 chloride, $99 \mathrm{mTc}$ tetrofosmin, $99 \mathrm{mTc}$ methylene diphosphonate, radiolabeled antibodies and iodine-123 oestradiol [13-40]. A number of studies have demonstrated high diagnostic accuracy of 99mTc-MIBI for the detection of breast cancer [22-32]. Therefore, this multicentre trial was set up to confirm the value of scintimammography using $99 \mathrm{mTc}-\mathrm{MIBI}$.

\section{Material and methods}

Study design

The study has been a prospective open-label multicentre trial to determine the diagnostic accuracy of $99 \mathrm{mTc}-\mathrm{MIBI}$ scintigraphy for the identification of malignant breast lesions in two groups of patients (Fig. 1): (1) patients with mammographically detected, non-palpable breast abnormalities; (2) patients with breast abnormalities detected by palpation. Further objectives have been: (3) to compare the diagnostic accuracy of sestamibi imaging with that of mammography, (4) to establish whether the diagnostic performance of

Subjects who have undergone mammography and are positive for (a) at least one palpable breast abnormality detected

by physical examination

OR

(b) at least one breast abnormality detected by mammography within the previous 3 weeks and are scheduled to undergo excisional biopsy are ENROLLED

$\Downarrow$

Bolus injection of $99 \mathrm{~m} \mathrm{Tc}-\mathrm{MIBI}$ administered within 3 weeks of mammography and physical examination $\Downarrow$

5 min p.i. start of 10-min lateral image acquisitions, followed by anterior image

$\Downarrow$

10-min lateral acquisition repeated $1 \mathrm{~h}$ p.i. (optional) $\Downarrow$

EXCISIONAL BIOPSY performed within 6 weeks following $99 \mathrm{mTc}-\mathrm{MIBI}$ study

Fig. 1. Flow chart of the prospective trial with $99 \mathrm{mTc}-\mathrm{MIBI}$. the imaging technique can be improved by modifying the method of interpretation and (5) to acertain whether use of the two techniques, scintigraphy and mammography, in conjunction provides a better predictive capability than either technique used alone.

Axillary tracer uptake had been documented on the case report forms. Since only a few patients showed axillary uptake of $99 \mathrm{mTc}-$ MIBI, these data are not presented in this paper. It was not the aim of the trial to evaluate ${ }^{99 \mathrm{~m}} \mathrm{Tc}-\mathrm{MIBI}$ for the detection of lymph node metastases.

\section{Patients}

Inclusion and exclusion criteria for entry into the trial are listed in Table 1. Data were received for 246 patients (Table 2), from a total of nine sites (Italy 71 patients, France 64 patients, Spain 42 patients, Germany 37 patients, Belgium including two centres, 21 patients, Great Britain 7 patients, Switzerland 4 patients). The data of centres recruiting less than 20 patients were pooled. Since no

Table 1. Inclusion and exclusion criteria for entry into the trial

\section{INCLUSION CRITERIA}

1. Female older than 21 years, non-pregnant, non-lactating

2a. Suspicious lesion of the breast detected by physical examination and scheduled for mammography within the next 3 weeks

2b. Suspicious lesion detected by mammography in the previous 3 weeks

3. Recommendation for excisional biopsy, after mammography, but within 6 weeks following ${ }^{99 m}$ Tc-MIBI study

4. Informed consent.

\section{EXCLUSION CRITERIA}

1. Previous mastectomy (modified) of breast with suspicious lesion

2. Local tumour recurrence

3. Fine-needle biopsy within 1 week prior to scintimammography

4. Receipt of an investigational drug within 10 physical half-lives prior to ${ }^{99 \mathrm{~m}} \mathrm{Tc}$ - MIBI

Table 2. Patient population of the trial

\begin{tabular}{lll}
\hline Data collection: 246 patients & Centre & \multicolumn{2}{c}{ Number } \\
\cline { 2 - 3 } & Italy & 71 \\
& France & 64 \\
& Spain & 42 \\
& Germany & 37 \\
& Pooled centres & 32 \\
& \\
Efficacy population & \\
Patients: & 232 patients, after exclusion of \\
& 14 patients \\
Lesions: & 253 lesions (21 patients with \\
& 2 examined lesions \\
& 195 palpable and 58 non- \\
Mean age: & palpable lesions \\
Mean weight. & 54.5 years \\
Post-/peri-/premenopausal: & $64.0 \mathrm{~kg}$ \\
\hline
\end{tabular}


excisional biopsy had been performed, 14 patients were excluded from the efficacy population, thus leaving 232 patients in this population. The overall ratio of palpable to mammographically detected lesions was about 3:1. The number of lesions in the "by lesion" efficacy population was 253 (195 lesions detected by palpation and 58 lesions detected by mammography). In 21 cases, patients had two pathological lesions of the breast (ten bilateral cancers).

The mean age and weight for patients with palpable lesions and mammographically detected lesions were 53.4 years and $63.1 \mathrm{~kg}$ and 56.4 years and $65.5 \mathrm{~kg}$, respectively (range 21-87 years and $40-159 \mathrm{~kg}$ ). The majority $(95.5 \%)$ of patients were Caucasian. A history of pregnancy was indicated for $74 \%$ of patients, with age at first pregnancy varying between 15 and 39 years (mean 24.5). In $18 \%$ of patients, a family history of breast cancer was present. Oral contraceptive usage and hormone replacement therapy were indicated in $10 \%$ and $7 \%$, respectively. Sixty percent of women were postmenopausal. Pre- and perimenopausal status was documented in $30 \%$ and $8 \%$ of patients, respectively. Surgical biopsy, found to be benign, had been previously conducted in $14 \%$ of patients. Mastectomy and lumpectomy of the contralateral breast had been carried out in $4 \%$ and $6 \%$ of patients.

\section{Scintigraphy}

Radiopharmaceutical. The radiolabelling and quality control procedures for the preparation of ${ }^{99 \mathrm{~m} T c-M I B I}$ (Dupont Pharma) were carried out according to the manufacturer's instruction. The vial preparation requires reconstitution with sodium $99 \mathrm{mTc}$ pertechnetate followed by heating in a water bath. In order to be used, the radiochemical purity of the radiopharmaceutical had to be greater than or equal to $90 \%$.

Patient preparation and administration. Each patient received an intravenous injection into the arm on the side contralateral to the breast lesion. A "cold" injection with $10 \mathrm{ml}$ saline solution was administered after the injection of $99 \mathrm{mTc}$-MIBI. The average dose was $20 \mathrm{mCi}$ (range 18-30 mCi). No meal was consumed between injection and imaging; water intake was unrestricted, however. When both breasts had a palpable or mammographically determined abnormality, the injection was given in a dorsalis pedis vein.

The subject was initially examined in the prone position with the arms raised above the head, the shoulders flat against the table, and the head turned to one side. For lateral views, a special table overlay was used to provide maximal separation of breast tissue from the myocardium and the liver. This overlay consisted of a foam cushion with two cut-offs at the lateral side. Then the patient was imaged in the supine position.

Imaging. Planar imaging was started 5 min after the injection of 99mTc-MIBI. The imaging sequence was as follows: (1) 10-min lateral view $90^{\circ}$ acquisition of the breast with the suspected lesion, (2) 10-min lateral view $90^{\circ}$ acquisition of the other breast, following repositioning of the subject, (3) 10-min anterior view with the subject positioned supine and her arms raised behind her head. Delayed imaging $1 \mathrm{~h}$ post-injection was optional. Planar images were performed with a $256 \times 256$ matrix, a $10 \%$ window and an energy peak of $140 \mathrm{keV}$. A low-energy high-resolution collimated gamma camera without zoom was used. The camera was positioned as close as possible to the breast. A minimum number of 500000 counts (field of view) per $40 \mathrm{~cm}$ head standardized had to be acquired. For the first two subjects enrolled in the study at each centre, 50 pixels in the breast were measured to allow comparative quantification.

\section{Mammography}

The analysis of mammograms is based on the institutional read. A standard mammographic examination had to be applied to all patients. The mammographer assigned a probability of malignancy (PM) for each lesion detected. If there was more than one lesion in a breast, the PM was taken as the maximum recorded level for that breast. When the probability was not given as a percentage, but descriptively instead, probabilities were assigned according to the following classification:

$\begin{array}{ll}\text { Description } & \text { Percentage } \\ \text { Low } & 20 \% \\ \text { Medium/suspicious } & 50 \% \\ \text { High } & 70 \% \\ \text { Very suspicious } & 80 \%\end{array}$

If no lesion was detected mammographically in that breast, the PM was assigned as zero. For analysis, PMs were grouped into ordered categories: $0 \%-24 \%, 25 \%-49 \%, 50 \%-74 \%$ and $75 \%-$ $100 \%$. For the calculation of sensitivity/specificity statistics, mammography was taken as indicating malignancy if the assessed $\mathrm{PM}$ was $50 \%$ or greater.

\section{Institutional and blinded read scintigraphy}

For each lesion, a maximum of four images were assessed, an initial and a delayed image for both lateral and anterior views. The delayed image was optional. Each set of images was assessed by an institutional reader and a panel of four blinded readers. The institutional reader used both the initial and delayed images if available (but for the delayed image scored only the lateral view). The blinded readers scored the initial and the delayed views separately without knowing that they were from the same patient. For each view, the image was assessed in each of a number of segments [six per breast for the lateral view, four per breast for the anterior view plus the axillary nodes (one score per breast)]. Each segment was assessed using the following scale (Figs. 2 and 3):

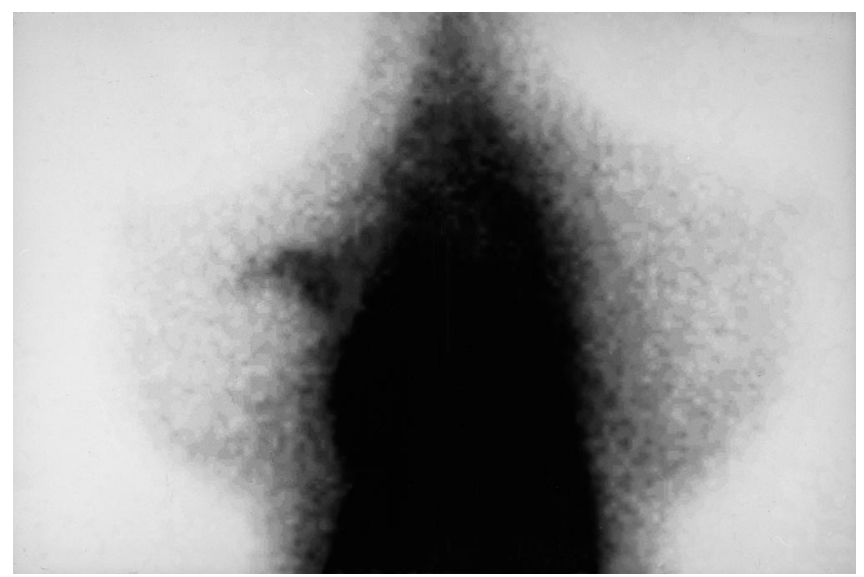

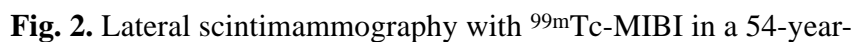
old patient with a palpable lesion in the left breast. Focal accumulation is observed in the upper part of the left breast, corresponding to a histopathologically confirmed invasive ductal cancer (diameter $2.0 \mathrm{~cm}$ ). This scan was scored as 2 by the blinded read and considered as a true-positive scintigram for definition 1 


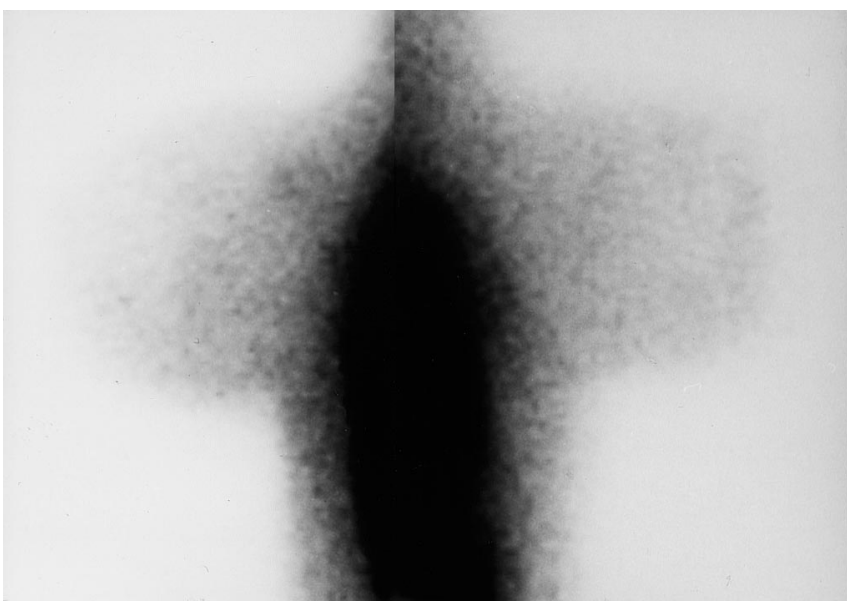

Fig. 3. Lateral scintimammography with ${ }^{99} \mathrm{~m}$ Tc-MIBI in a 61 -yearold patient with a palpable lesion in the left breast. Slightly increased tracer uptake is observed in the upper part of the left breast. Histopathology revealed an invasive ductal cancer with a maximum diameter of $1.1 \mathrm{~cm}$. This scan was scored as 1 by the blinded read and considered as a true-positive scintigram for definition 2

\section{0 : Normal \\ 1: Equivocal \\ 2: Focal uptake - low intensity \\ 3: Focal uptake - medium intensity \\ 4: Focal uptake - high intensity}

The blinded read was blinded in the sense that the assessors were ignorant of the centre at which the images were taken, and of any other ancillary medical information about the patient. Each assessor scored the images independently.

For the primary assessment of diagnostic accuracy, any breast with a maximum segment score of 2 or greater was interpreted as a positive result (definition 1). A secondary assessment was also made, in which a positive result was assumed if the maximum score was 1 or greater (definition 2). For the blinded read, the assessment based on the delayed view was made separately from that using the early views, but only the information from the early views was used for making comparisons with other assessment methods.

For the interpretation of the blinded read panel results, a breast was deemed to be positive if at least two of the four assessors scored the breast as such. As only in 3\% of the blinded read scintigrams did two readers each score a scan positive and negative, there was no further consensus reading. Data had to be available for at least three of the assessors for this procedure to be applied; otherwise, the diagnosis was regarded as missing.

The blinded read assessors also scored the images for quality; each of the four images (early and delayed, lateral and anterior) was scored separately on a four-point scale: 1, excellent; 2, good; 3 , fair; 4 , poor. To obtain an overall assessment for each reader, an average value for the four scores was calculated. To obtain an average across readers, the numerical average of 16 observations (four readers by four views) was calculated.

\section{Histopathology}

An excisional biopsy was taken in all evaluated patients. This was diagnosed by the institutional pathologist and the diagnosis was later confirmed (in all but three cases) by the core centre pathologist. The measurement of the tumour size was based on the insti-

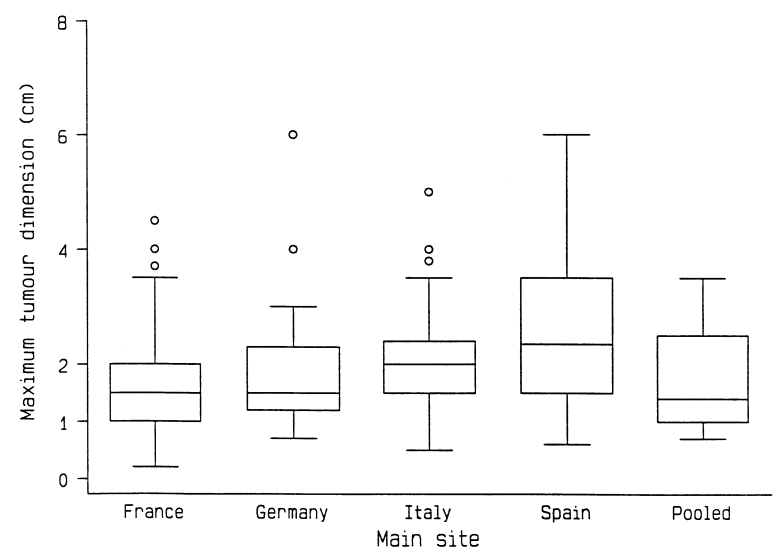

Fig. 4. Tumour size (mean maximum tumour dimension and range of tumour size) according to the site of the participating centre (pooled $=$ all patients of the smaller centres)

tutional results. Analysis by tumour size was done for the largest dimension given. Where two lesions were excised from the same breast, the size of the larger lesion was used. The core centre diagnosis was taken as indicating malignancy (for the primary analysis) if either of the following description boxes was ticked: (1) type of invasive cancer, (2) ductal carcinoma in situ (DCIS). For a secondary analysis, lobular carcinoma in situ (LCIS) and ductal and/or lobular hyperplasia as indicators for an increased breast cancer risk were also regarded as true-positive results.

Core centre histopathology diagnosed 109 invasive ductal and 29 invasive lobular cancers, 11 DCIS, two metastases, six tubular carcinoma, two medullary carcinomas and two papillary carcinomas. Furthermore, one mucinous cancer, one case of Paget's disease, one malignant cystosarcoma phylloides and one sarcoma have been revealed. Among the benign alterations, there were 37 fibroadenomas, 25 fibrocystic changes, six fat necrosis, five inflammatory processes, four LCIS, three scleradenosis, three normal breasts, two scars, two adenomas and one hemangioma.

The tumour sizes reported at the main participating centres are shown in Fig. 4. The average maximum tumour dimension ranged from $1.3 \mathrm{~cm}$ (pooled centres) over $1.5 \mathrm{~cm}$ (France, Germany) and $2.0 \mathrm{~cm}$ (Italy) to $2.4 \mathrm{~cm}$ (Spain). Forty-one cancers had a maximal diameter of below $1 \mathrm{~cm}, 37$ a maximum diameter between $1.0 \mathrm{~cm}$ and $1.5 \mathrm{~cm}$ and 87 a maximum diameter of more than $1.5 \mathrm{~cm}$.

\section{Data analysis}

All data were collected on case report forms (CRFs) which had been distributed to all participating centres. All CRF data were entered into a database and converted to SAS datasets for delivery and into STATA datasets for analysis.

The safety population of the trial consisted of all patients who received the $99 \mathrm{mTc}-\mathrm{MIBI}$ imaging agent. To be included in the efficacy population patients had to meet the following criteria: (1) have had a biopsy for which a core centre microscopic diagnosis exists, (2) have blinded read data for the scintigraphy. The so called by lesion efficacy population consisted of all lesions for which a core centre microscopic diagnosis exists. Some classes of protocol violators were identified which were, however, not considered sufficient to warrant exclusion from the efficacy population. These were: (1) no mammography (two patients), (2) mammography more than 2 months prior to the scintigraphy (six patients who had no discrepancy between mammographic and scintigraphic results), (3) biopsy more than 6 weeks after the scintigraphy (19 patients, of whom four showed false-positive scintigrams 
and one a false-negative scintigram). Among these 27 patients (12 malignant and 15 benign lesions), there were three false-negative and five false-positive blinded read scintigrams referring to definition 2. The exclusion of these patients did not result in any alteration in sensitivity and specificity as shown in the Results section. All efficacy analyses were made separately for each target group of patients: (1) mammographically detected breast abnormalities, (2) breast abnormalities detected by palpation.

The measurement of agreement between any two assessment methods was based on a two-by-two table, in which one of the classifying factors was the gold standard (e.g. core centre histopathological results). From the tables, the following statistics were derived: sensitivity, specificity, overall agreement, kappa, positive predictive value (PPV) and negative predictive value (NPV). For the assessment of whether one technique is better than another, four-by-four tables were created indicating false-negative and false-positive, and true-negative and true-positive results of the methods. Several different types of assessment were evaluated: (1) institutional centre sestamibi read (definition 1 and definition 2) compared to core centre histopathology, (2) blinded sestamibi read (definition 1 and definition 2) compared to core centre histopathology, 3. comparison between institutional and blinded read scintigraphy, (4) comparison between blinded read scintigraphy and mammography.

\section{Safety assessment}

The numbers of patients experiencing any adverse event were tabulated. Adverse events had to be classified by type of event and summarized accordingly. Any serious event had to be tabulated separately.

\section{Results}

\section{Scintigraphic blinded read}

When the results of the blinded read were compared with the histopathological results of the core centre, scintigraphy was true-positive in 117 of 165 cancers (definition 2). This resulted in an overall sensitivity of $71 \%$ (Table 3 ). In this group, sensitivity for palpable and non-palpable cancers was $83 \%$ and $30 \%$, respectively. For tumours bigger than $1.5 \mathrm{~cm}$, sensitivity was $90 \%$. For tumours between 1.0 and $1.5 \mathrm{~cm}$ and for those smaller than $1 \mathrm{~cm}$, sensitivity was $65 \%$ and $40 \%$, respectively.

If only scintigrams scored 2 or more were taken into account (definition 1), overall sensitivity was only $61 \%$. In this group, sensitivity was $72 \%$ for the palpable $(n=127)$ and $21 \%$ for the non-palpable cancers $(n=38$; Tables 3 and 4). For tumours bigger than $1.5 \mathrm{~cm}$, sensitivity was higher, with a value of $80 \%$.

Among 88 benign alterations of the breast, there were 68 palpable and 20 non-palpable lesions (Table 5). Overall specificity was $69 \%$ (definition 2, 27/88 false-positives scans) and 81\% (definition 1, 17/88 false-positive scans). For palpable lesions, specificity was $75 \%$ (defintion 2) and $79 \%$ (definition 1), respectively, and for lesions bigger than $1.5 \mathrm{~cm}$, specificity was $72 \%$ (definition 2) and $78 \%$ (definition 1 ).

When the results of the blinded read were separated out by main sites, the sensitivities and specificities were
Table 3. Sensitivities (Sens) and specificities (Spec) of blinded read scintimammography according to the scoring mode

\begin{tabular}{llll}
\hline & $\begin{array}{l}\text { All } \\
(\text { Sens/Spec })\end{array}$ & $\begin{array}{l}\text { Palpable } \\
(\text { Sens/Spec })\end{array}$ & $\begin{array}{l}\text { Non-palpable } \\
(\text { Sens/Spec) }\end{array}$ \\
\hline Definition 1 & $61 \% / 81 \%$ & $72 \% / 79 \%$ & $21 \% / 85 \%$ \\
Definition 2 & $71 \% / 69 \%$ & $83 \% / 75 \%$ & $30 \% / 50 \%$ \\
\hline
\end{tabular}

Definition $1=$ all lesions scored as 2 or more considered positive, definition $2=$ all lesions scored as 1 or more considered positive

Table 4. Results of blinded read scintimammography in respect of malignant lesions (numbers in parentheses), according to the scoring mode

\begin{tabular}{llllllllll}
\hline & \multicolumn{2}{c}{ All (165) } & & \multicolumn{2}{c}{ Palpable (127) } & & \multicolumn{2}{c}{ Non-palpable (38) } \\
\cline { 2 - 3 } Scoring mode & TP & FN & & TP & FN & & TP & FN \\
\hline Definition 1 & 100 & 65 & & 92 & 35 & & 8 & 30 \\
Definition 2 & 117 & 48 & & 106 & 21 & & 11 & 27 \\
\hline
\end{tabular}

Definition $1=$ all lesions scored as 2 or more considered positive; definition $2=$ all lesions scored as 1 or more considered positive; $\mathrm{TP}$, true-positives; FN, false-negatives

Table 5. Results of blinded read scintimammography in respect of benign lesions (numbers within parentheses), according to the scoring mode

\begin{tabular}{lllllllll}
\hline & \multicolumn{2}{c}{ All (88) } & & \multicolumn{2}{c}{ Palpable (68) } & & \multicolumn{2}{l}{ Non-palpable (20) } \\
\cline { 2 - 3 } Scoring mode & TN & FP & & TN & FP & & TN & FP \\
\hline Definition 1 & 71 & 17 & & 54 & 14 & & 17 & 3 \\
Definition 2 & 61 & 27 & & 51 & 17 & & 10 & 10
\end{tabular}

Definition $1=$ all lesions scored as 2 or more considered positive; definition 2 all lesions scored as 1 or more considered positive; $\mathrm{TN}$, true-negatives, FP, false-positives

as follows (definition 1, Table 6): $87 \%$ and $84 \%$ (Spain), $87 \%$ and $77 \%$ (Italy), $61 \%$ and $78 \%$ (Germany), $46 \%$ and $100 \%$ (pooled centres) and $40 \%$ and $71 \%$ (France). If the pooled smaller centres were excluded, the overall sensitivity improved slightly to $63.5 \%$ but the specificity remained constant at $80 \%$ (definition 1).

If the 27 patients with "acceptable" protocol violations were excluded, the overall sensitivity and specificity did not change, with values of $70.6 \%$ (108/153 truepositives) and $70 \%$ (51/73 true-negatives), respectively (definition 2).

\section{Institutional read}

If the histopathological results were correlated to the institutional read the overall sensitivity and specificity, the PPV and the NPV were $88 \%, 66 \%, 84 \%$ and $72 \%$, respectively (for definition 2 ; Table 7 ). In this group, sen- 
Table 6. Sensitivities and specificities of blinded read and institutional scintimammography separated by participating centres (referring to definition 1)

\begin{tabular}{llllll}
\hline Centre & Italy & France & Spain & Germany & Pooled centre \\
\hline $\begin{array}{l}\text { Blinded read } \\
\text { (Sens/Spec) }\end{array}$ & $87 \% / 77 \%$ & $40 \% / 71 \%$ & $87 \% / 84 \%$ & $61 \% / 78 \%$ & $46 \% / 100 \%$ \\
$\begin{array}{l}\text { Institutional } \\
\text { (Sens/Spec) }\end{array}$ & $93 \% / 83 \%$ & $73 \% / 43 \%$ & $87 \% / 80 \%$ & $83 \% / 56 \%$ & $71 \% / 100 \%$ \\
\hline
\end{tabular}

Sens, Sensitivity; Spec, Specificity
Table 7. Sensitivities (Sens) and specificities (Spec) of institutional read scintimammography depending on the scoring mode

\begin{tabular}{llll}
\hline & $\begin{array}{l}\text { All } \\
(\text { Sens/Spec })\end{array}$ & $\begin{array}{l}\text { Palpable } \\
(\text { Sens/Spec })\end{array}$ & $\begin{array}{l}\text { Non-palpable } \\
\text { (Sens/Spec) }\end{array}$ \\
\hline Definition 1 & $81 \% / 74 \%$ & $86 \% / 69 \%$ & $63 \% / 81 \%$ \\
Definition 2 & $88 \% / 66 \%$ & $91 \% / 65 \%$ & $60 \% / 93 \%$ \\
\hline
\end{tabular}

Definition $1=$ all lesions scored as 2 or more considered positive; definition $2=$ all lesions scored as 1 or more considered positive

sitivity for palpable and non-palpable lesions was $91 \%$ and $60 \%$, respectively. For tumours bigger than $1.5 \mathrm{~cm}$, sensitivity was $95 \%$. For tumours between 1.0 and $1.5 \mathrm{~cm}$ and for those smaller than $1 \mathrm{~cm}$, sensitivity was $74 \%$ and $55 \%$, respectively.

If definition 1 was used the overall sensitivity and specificity, the PPV and the NPV were calculated to be $81 \%, 74 \%, 86 \%$ and $65 \%$, respectively. In this group, sensitivity and specificity for palpable and non-palpable lesions of the breast were $86 \%$ and $69 \%$, and $63 \%$ and $81 \%$, respectively.

The institutional results by main sites were as follows: sensitivity and specificifity were $93 \%$ and $83 \%$ for the Italian centre, $87 \%$ and $80 \%$ for the Spanish centre, $83 \%$ and $56 \%$ for the German centre, $73 \%$ and $43 \%$ for the French centre and $71 \%$ and $100 \%$ for the pooled centres (definition 1, Table 6). If the pooled smaller centres were excluded, the overall sensitivity improved slightly to $83 \%$ with a minimal decrease in specificity to $72 \%$ (definition 1).

\section{Mammography}

When comparing mammographic results with the core centre microscopy, mammography was true-positive in 152 of 165 cancers and true-negative in 37 of 88 benign alterations of the breast. This results in a sensitivity and specificity of $91 \%$ and $42 \%$, respectively. Sensitivity was not dependent on the size of the breast tumour (for tumours $>1.5 \mathrm{~cm}, 90.7 \%$, for those between 1.0 and $1.5 \mathrm{~cm}, 96 \%$, and for those $<1.0 \mathrm{~cm}, 87 \%$; non-palpable $88 \%$ and palpable $92 \%$ ). In the category of probability of malignancy of $50 \%-74 \%$, mammography underestimated the real cancer probability for palpable breasts but overestimated it for non-palpable breasts. If mammogra-
Table 8 Comparison of mammographic and blinded read scintigraphic results (referring to definition 2)

\begin{tabular}{lcccl}
\hline $\begin{array}{l}\text { Mammographic } \\
\text { results }\end{array}$ & \multicolumn{5}{l}{ Scintigraphic results } \\
\cline { 2 - 5 } & TP & FP & FN & TN \\
\hline TP & 109 & - & 43 & - \\
FP & - & 15 & - & 36 \\
FN & 8 & - & 5 & - \\
TN & - & 12 & - & 25 \\
\hline
\end{tabular}

TP, True-positives; FP, false-positives; FN, false-negatives; TN, true-negatives

Table 9. Results of mammography, scintigraphy and histology in patients showing a false-negative mammogram and a true-positive scintigram

\begin{tabular}{lllrll}
\hline Patient & $\begin{array}{l}\text { Breast } \\
\text { density }\end{array}$ & MX & PM & SMM & Histology \\
\hline 1 & HeD & MC, no mass & $20 \%$ & Acc, 2 & Inv. duct, G2 \\
2 & ExD & MC, no mass & $30 \%$ & Acc, 3 & Medullary, G3 \\
3 & HeD & Mass & $20 \%$ & Acc, 3 & Inv. duct, G2 \\
4 & HeD & Mass & $10 \%$ & Acc, 2 & Metastasis \\
5 & ExD & No mass & $0 \%$ & Acc, 2 & Inv. lobular G1 \\
6 & ExD & No mass & $0 \%$ & Acc, 2 & Inv. duct, G2 \\
7 & NvD & Mass & $20 \%$ & Acc, 2 & Inv. duct, G1 \\
8 & HeD & No mass & $0 \%$ & Acc, 3 & Inv. duct, G1 \\
\hline
\end{tabular}

MX, Mammography; SMM, scintigraphy; PM, probability of malignancy; $\mathrm{HeD}$, heterogeneously dense; ExD, extremely dense; $\mathrm{NvD}$, numerous vague densities; MC, microcalcifications; Acc $2 / 3$, focal accumulation with score 2 or 3 ; inv. duct, invasive ductal carcinoma; inv. lobular, invasive lobular carcinoma

phy and blinded read scintigraphy were compared, eight cancers scored true-positive by the blinded read scintigraphy had been indicated by mammography to be falsenegative (Table 8). This means that in $61 \%$ of all falsenegative mammograms scintigraphy could diagnose the cancer. The aforementioned eight cancers (seven palpable, one detected by ultrasonography) were studied by different centres participating in the trial. Except for one breast, the corresponding mammograms showed dense breast tissue. In five of the eight malignant tumours, no suspicious mass could be detected, and microcalcifications were present only in two breasts (Table 9). Just one patient was postmenopausal. 


\section{Density of breasts}

Sensitivity of blinded read scintigraphy was not dependent on the density of breast tissue. Of 165 cancers, 118 (72\%) were categorized as located in a breast of mammographic grade I or II density (group 1) and 47 (28\%) as located in a grade III/IV density breast (group 2). The mean tumour diameter in groups 1 and 2 was 1.9 and $1.8 \mathrm{~cm}$, respectively. Overall-sensitivity of the blinded read scintigraphy (definition 2) for the first and second groups was $70 \%$ (83 true-positives from 118 cancers) and $72 \%$ (34 true-positives from 47 cancers), respectively.

\section{Time of imaging}

As delayed images were optional, comparison of the early and delayed blinded read scintigrams was confined to 176 breasts. Using definition 1, 30\% of the breasts were found to be positive on the early reads as compared with $26 \%$ on the delayed reads. Using definition 2 , reads of the early views yielded positive results in $38 \%$ compared with $31 \%$ for the delayed reads. Only in three cases did the early view give a false-negative result while the delayed read was true-positive.

\section{Kappa-statistics}

Overall, the agreement between the readers of the blinded scintigraphy read did not show a significant difference if definition 1 was compared with definition 2 . Overall agreement referring to all breasts was high, at 0.812 and 0.793 , respectively. In $97 \%$ of the cases, three or more readers agreed in scoring a scintigram either positive or negative (definition 1). The reader agreement was somehow better for palpable lesions than for mammographically detected lesions. This difference in kappa values was more significant if definition 1 was used. With decreasing quality of images, the kappa value fell slightly but always remained above 0.7 . In each quality class, the same high percentage of reader agreement (three or more readers scoring either positive or negative) could be found with values of $94 \%-96 \%$. One main reason for disagreement between the readers was the way axillary nodes have been handled. These were entered as axillary nodes by some readers but as being in one of the breast segments by others.

When comparing the blinded and the institutional read, the overall kappa value for the agreement was 0.63 . For palpable lesions, the agreement was better, with a value of 0.7 . The decrease in kappa values with the quality score was more significant than mentioned before between the blinded readers. The main reason for the differences in diagnoses of blinded and institutional reads was that the institutional readers assigned higher scores to lesions than did the blinded readers, especially where the lesion was indistinct.

\section{Histopathology}

With regard to the histopathological characterization of the cancer, the sensitivity of the blinded read (definition 2) for invasive ductal cancers (80 true-positives from 109), invasive lobular cancers (20 true-positives from 29) and ductal carcinoma in situ (seven true-positives from 11) was $74 \%, 69 \%$ and $64 \%$, respectively. The blinded read correctly diagnosed two metastases, two medullary cancers, one sarcoma and one malignant cystosarcoma phylloides. Among six tubular and two papillary cancers, blinded read scintigraphy was true-positive in three and one cases, respectively, but could not diagnose one mucinous carcinoma and one case of Paget's disease (Table 10).

If the histopathological results of the benign alterations are taken into account, specificity for fibroadenomas and fibrocystic disease was $68 \%$ and $88 \%$ (definition 2 ), respectively. Among the six cases of fat necrosis, five inflammations of the breast, two scars and one haemangioma, blinded read scintigraphy was true-negative in four, two, one and one cases, respectively. In two adenomas and three cases of normal breast tissue, results were truenegative in two cases each. All three breasts with scleradenosis showed false-positive scintigrams (Table 11).

Table 10. Results of scintimammography (SMM; definition 2; blinded read) according to the histological type of breast cancer

\begin{tabular}{lrcc}
\hline Histology & No. & TP-SMM & FN-SMM \\
\hline Inv. ductal & 109 & 80 & 29 \\
Inv. lobular & 29 & 20 & 9 \\
DCIS & 11 & 7 & 4 \\
Tubular & 6 & 3 & 3 \\
Others & 10 & 7 & 3 \\
All & 165 & 117 & 48 \\
\hline
\end{tabular}

Inv., Invasive; DCIS, ductal carcinoma in situ; TP-SMM, true-positive SMM; FN-SMM, false-negative SMM

Table 11. Results of scintimammography (SMM; definition 2; blinded read) according to the histological type in benign lesions

\begin{tabular}{lrcc}
\hline Histology & No. & TN-SMM & FP-SMM \\
\hline Fibroadenoma & 37 & 25 & 12 \\
Fibrocystic tissue & 25 & 22 & 3 \\
Fat necrosis & 6 & 4 & 2 \\
Inflammation & 5 & 2 & 3 \\
LCIS & 4 & 4 & 0 \\
Others & 11 & 4 & 7 \\
All & 88 & 61 & 27
\end{tabular}

LCIS, Lobular carcinoma in situ; TN-SMM, true-negative SMM; FP-SMM, false-positive SMM 


\section{Discussion}

Recently, nuclear breast imaging has gained significant interest as several radionuclides have demonstrated promising results in the diagnosis of breast cancer. $99 \mathrm{~m}$ Tc-MIBI is a cationic complex which can accumulate in tumour cells [41]. The accumulation of $99 \mathrm{~m} \mathrm{Tc}-\mathrm{MIBI}$ in the tumour is dependent on the quantity of mitochondria in the tumour cell, on the electric membrane potential and on the expression of the multidrug resistance (MDR) gene [42-46].

Recent studies using 99mTc-MIBI for breast cancer detection have shown high sensitivity and specificity for palpable cancers [22-32]. For non-palpable breast lesions, diagnostic accuracy has been less favorable [25, $27,29,30]$. In this trial, scintigraphy with $99 \mathrm{mTc}-\mathrm{MIBI}$ read blinded achieved an overall sensitivity of $71 \%$. For palpable tumours and tumours bigger than $1.5 \mathrm{~cm}$, sensitivity was $83 \%$ and $90 \%$, respectively. Specificity in these two groups was clearly over $70 \%$. These values are slightly below those reported by previous studies [23-30]. Generally, it can be expected that it will be more difficult to obtain similar results if the method is assessed by a blinded multicentre study. Consequently, in this trial, the institutional read demonstrates an increase in the overall sensitivity in all centres up to a value of $88 \%$ when compared with the blinded read. It must be supposed that the clinical data such as size of lesion, location and probability of malignancy are important factors for the reader of scintigraphy and their knowledge will increase sensitivity. In the case of palpable lesions and lesions bigger than $1.5 \mathrm{~cm}$, sensitivity increased to $91 \%$ and $96 \%$, respectively, by the institutional read. These results are in agreement with a multicentre trial conducted in the United States and Canada which revealed an institutional sensitivity of $95 \%$ for palpable lesions [47].

In this study, it has been shown that sensitivity can be significantly increased if lesions which are scored as equivocal are considered as a malignant process. Even if this definition was used, specificity did not fall below a level of $70 \%$. This means that any abnormality must be considered as suspicious for malignancy. In this way, a high sensitivity of scintimammography in association with an acceptable specificity can be achieved (Fig. 5). As demonstrated by the ROC curves, there will be a learning process for the interpretation of scintigrams resulting in an increase in sensitivity.

There are still significant limitations to the use of mammography for the detection of breast cancer, and these limitations persist in spite of technical improvements facilitating dianosis. Especially in younger women (less than 50 years old) with dense breasts, the diagnostic benefit of mammography is less favourable $[7,8]$. Thus, there is a need for a non-invasive method to complement mammography and to help differentiate benign and malignant breast lesions in dense breasts. Such a method should be reliable and have a high sensitivity

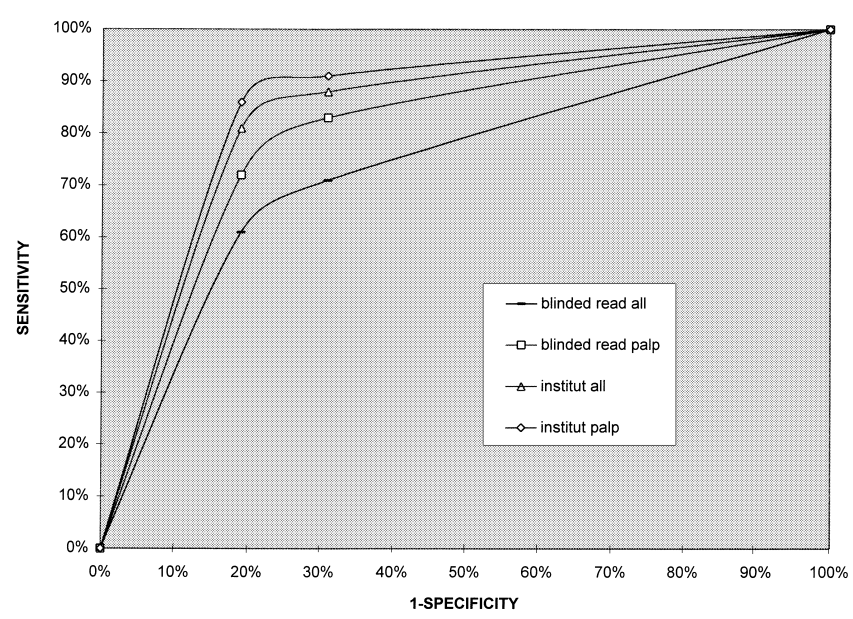

Fig. 5. ROC curves of blinded and institutional (institut) read scintigraphy for all and for palpable (palp) lesions. The first value of each curve refers to definition 1 and the second value of the curve refers to definition 2

and a high predictive value. In this trial, mammographic results were within the range of the values reported in the literature [48]. Overall sensitivity and specificity were $91 \%$ and $40 \%$, respectively. Sensitivity of mammography was not dependent on the tumour size, and, therefore, no decrease in sensitivity in patients with nonpalpable cancers was observed. In this trial, overall sensitivity of mammography was superior to that of scintigraphy, demonstrating that scintimammography, in its current state, is not suitable for breast cancer screening. For the mammograms, only an institutional read has been performed. This means that the mammographic results of this trial correspond to those of the clinical everyday practice of the radiologist.

However, this trial has shown that scintigraphy can provide additional information to mammography and help to detect breast cancer earlier in a subgroup of patients. In $60 \%$ of patients with a false-negative mammogram, scintigraphy could diagnose the breast cancer. This group consisted of younger patients with mammographically dense breast tissue resulting in a false-negative mammogram. As this study was able to prove, the diagnostic accuracy of scintimammography is not dependent on the density of breast tissue. This has also been reported by Khalkhali et al. [49, 50]. Consequently, premenopausal patients whose mortality from breast cancer cannot be decreased significantly by screening mammography will benefit most from scintimammography.

In the majority of the cases, the woman herself detects an alteration of the breast for which she consults the physician [51]. Sensitivity of breast palpation is not satisfactory, and often lumpy breasts make it difficult to characterize sufficiently a palpable nodule or mass in the breast [51]. If mammography performed in the further diagnostic work-up is indeterminate and suspicion of malignancy not high, the patient will be advised to return for a control mammography in 3-6 months. In this 


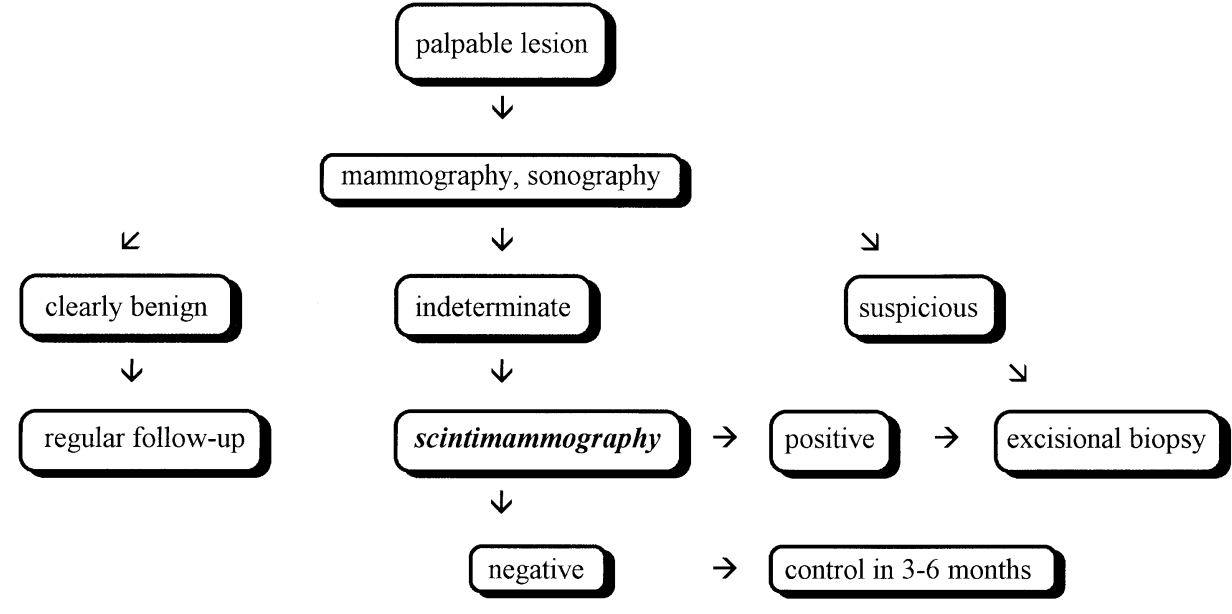

Fig. 6. Flow chart indicating the role of scintimammography in the diagnostic work-up of patients with palpable breast masses patient group, the majority of which comprises premenopausal women, scintigraphy could help to diagnose breast cancer at an earlier point in time when it is used as a complementary method to mammography (Fig. 6).

It is important for a breast cancer imaging modality that sensitivity is not dependent on the histological type of the cancer. For invasive ductal and lobular carcinomas, the sensitivity of scintimammography did not show a significant difference. This group of malignant tumours represent $80 \%-85 \%$ of all breast cancers [52]. For DCIS, sensitivity was slightly lower than for invasive cancers. Furthermore, less frequent cancers such as medullary and tubular carcinomas and metastases could also be diagnosed by scintimammography. This makes scintigraphy suitable as a complementary imaging method.

False-positive results were obtained in patients with fibroadenoma, fibrocystic disease and local inflammation of the breast. Disease with a high inflammatory component might yield false-positive results, most likely due to increased local perfusion. Areas with increased mitochondrial activity and density, such as juvenile adenomas and hyperproliferative disease, can also cause false-positive MIBI uptake [22, 25, 27, 29]. However, patients with atypical hyperproliferative disease have a higher relative risk for breast cancer [52]. In these patients, a positive MIBI scan may be of prognostic value [53].

The exact localization of a MIBI-positive area remains a problem since neither planar imaging nor singlephoton emission tomography provides the surgeon with sufficient information for biopsy of breast tissue. When scintimammography is indicative for breast cancer but other breast imaging modalities such as mammography, ultrasonography and magnetic resonance imaging are negative, the scintigram must be used for tumour localization. New approaches have been developed to allow scintigraphy-guided biopsy of breast lesions [54, 55].

It is known that mammogaphy is a very reader-dependent method. With regard to ultrasonography, this problem is even more important. The interreader agreement for scintimammography, however, is very high, with kappa values of 0.812 . It is important for a diagnostic method that the interreader variation is low, especially when it is performed in a wide medical field of clinical everyday practice.

Khalkhali et al. have shown that the prone position with the breasts hanging freely is the best technique for the performance of lateral scintimammography because deeper regions of the breast can be visualized [23]. For this purpose different techniques may be used: a special table design with a lateral cut-off or a kind of foam cushion with lateral apertures as used in this trial. Regardless of which technique is used, the breast must not be compressed from either side. Furthermore, a high-resolution gamma camera should be used and the acquisition time must be at least $10 \mathrm{~min}$ if good quality images are to be obtained. Special attention must be drawn to the distance between the collimator and the breast, which, ideally, should touch the camera surface. Standardization of scintimammography will help to achieve a high quality level of this technique.

Use of fluorine-18 fluorodeoxyglucose (18F-FDG) and positron emission tomography (PET) has also been evaluated for the detection of breast cancer [14-21]. In a larger patient group, Avril et al. reported a sensitivity and specificity for the detection of primary breast cancer of $88 \%$ and $78 \%$, respectively [18]. For small tumours, only low sensitivity was achieved. In a group of 20 patients, Palmedo et al. compared FDG PET and 99mTcMIBI scintimammography [19]; however, in 40 breasts with 22 lesions, FDG PET could not detect additional cancer in comparison with Tc-99m MIBI scintigraphy. Comparing these two imaging modalities, PET has the advantage of providing better spatial resolution, but the availability of FDG and PET is limited and costs are significantly higher.

\section{Conclusions}

Scintimammography with 99mTc-MIBI has a high diagnostic accuracy in palpable breast lesions. Sensitivity is 
not dependent on the mammographically determined density of the breast tissue. Scintimammography is suitable as a complementary method to mammography in patients with dense breasts and an intermediate or low probability of breast cancer. Further, patients with a high risk of breast cancer may benefit from radionuclide imaging with $99 \mathrm{mTc}-\mathrm{MIBI}$.

Acknowledgements. The authors thank Ms. M. Grace for coordinating the collaboration during the trial and for setting up the database of the study.

\section{References}

1. Kelsey JL, Gammon MD. The epidemiology of breast cancer. Cancer 1991;41:146-165.

2. Berg JW, Hutter RV. Breast cancer. Cancer 1995;75:257-269.

3. Sondik EJ. Breast cancer trends. Incidence, mortality and survival. Cancer 1994;74:995-999.

4. Andersson I. Mammographic screening and mortality from breast cancer: Malmö mammographic screening trial. Brit $J$ Med 1988;297:943-948.

5. Frisell J, Eklund G, Hellström L, et al. Randomized study of mammography screening - preliminary report on mortality in the Stockholm trial. Breast cancer research and treatment 1991;18:49-56.

6. Miller AB, Baines $\mathrm{CJ}$, To $\mathrm{T}$, et al. Canada national breast screening study. Can Med Assoc J 1992;147:1459-1476.

7. Lannin DR, Harris RP, Swanson FH, Edwards MS, Swanson MS, Pories WJ. Difficulties in diagnosis of carcinoma of the breast in patients less than fifty years of age. Surg Gynecol Obstet 1993;177:457-476.

8. Coveney EC, Geraghty JG, O'Laoide R, Hourihane JB, O'Higgins NJ. Reasons underlying negative mammography in patients with palpable breast cancer. Clin Radiol 1994;49: $123-125$

9. Smart CR, Myers MH, Gloeckler LA Implications from SEER data on breast cancer management. Cancer 1978;41:787-789.

10. Carter CL, Allen C, Henson DE. Relation of tumour size, lymph node status and survival in 2474 breast cancer patients. Cancer 1989;63:181-187.

11. Koscielny S, Tubiana M, Le MG, et al. Breast cancer. Relationship between the size of the primary tumour and the probability of metastatic dissemination. Br J Cancer 1984;49: 709-715.

12. Fisher B, Redmond C, Fisher ER, et al. Ten-year result of randomized clinical trial comparing radical mastectomy and total mastectomy with or without radiation. $N$ Engl J Med 1985; 312:674-681.

13. De Jager R, Abdel N, Serafini A,et al. Current status of cancer immunodetection with radiolabeled human monoclonal antibodies. Semin Nucl Med 1993;23:165-179.

14. Wahl RL, Cody RL, Hutchins GD, Mudgett EE. Primary and metastatic breast carcinoma: initial clinical evaluation with PET with the radiolabeled glucose analogue F-18 fluoro-2-deoxy-D-glucose. Radiology 1991;179:765-770.

15. Tse NY, Hoh CK, Hawkins RH, Zinner MJ, Dahlbom M, Choi Y, Maddahi J, Brunicardi FC, Phelps ME, Glaspy JA. The application of positron emission tomographic imaging with FDG to the evaluation of breast disease. Ann Surg 1992;216:27-34.

16. Nieweg OE, Kim EE, Wong WH, Broussard WF, Singletary SE, Hortobagyi GN, Tilbury RS. Positron emission tomogra- phy with FDG in the detection and staging of breast cancer. Cancer 1993;71:3920-3925.

17. Adler LP, Crowe JP, Al Kaisi NK, Sunshine JL. Evaluation of breast masses and axillary lymph nodes with F-18 deoxy-2fluoro-D-glucose PET. Radiology 1993;187:743-750.

18. Avril N, Dose J, Jänicke F, et al. Metabolic characterization of breasts tumours with PET using F-18 fluorodeoxyglucose. $J$ Clin Oncol 1996;14:1848-1856.

19. Palmedo H, Bender H, Grünwald F et al. Comparison of fluorine-18 fluorodeoxyglucose positron emission tomography and Tc-99m methoxyisobutylisonitrile scintimammography in the detection of breast tumours. Eur J Nucl Med 1997;24: $1138-1145$

20. Scheidhauer K, Scharl A, Pietrzyk U, et al. Qualitative F-18 FDG positron emission tomography in primary breast cancer: clinical relevance and practicability. Eur J Nucl Med 1996;23: 618-623.

21. Crowe JP, Adler LP, Shenk RR, Sunshine J. Positron emission tomography and breast masses: comparison with clinical, mammographic, and pathological findings. Ann Surg Oncol 1994;1:132-140.

22. Kao CH, Wang SJ, Liu TJ. The use of technetium-99m methoxyisobutylisonitrile breast scintigraphy to evaluate palpable breast masses. Eur J Nucl Med 1994;21:432-436.

23. Khalkhali I, Mena I, Jouanne E, et al. Prone scintimammography in patients with suspicion of breast cancer. J Am Coll Surg 1994;178:491-497.

24. Khalkhali I, Cutrone JA, Mena I. Scintimammography: the complementary role of Tc-99m sestamibi prone breast imaging for the diagnosis of breast carcinoma. Radiology 1995; 196:421-426.

25. Khalkhali I, Cutrone JA, Mena I, Diggles L, Venegas R, Vargas H, Jackson B, Klein S. Technetium-99m-sestamibi scintimammography of breast lesions: clinical and pathological follow-up. J Nucl Med 1995;36:1784-1789.

26. Palmedo H, Grünwald F, Bender H, Schomburg A, Mallmann P, Krebs D, Biersack HJ. Scintimammography with Tc-99m MIBI: comparison with mammography and magnetic resonance imaging. Eur J Nucl Med 1996;23:940-946.

27. Palmedo H., Schomburg A, Gruenwald F, Mallmann P., Krebs D, Biersack HJ. Scintimammography with Tc-99m MIBI in suspicious breast lesions. J Nucl Med 1996;37:626-630.

28. Palmedo H, Schomburg A, Mallmann P, et al. (1996) Scintimammography with Tc-99m MIBI in patients with suspicion of primary breast cancer. Nucl Med Biol 1996;23:681-684.

29. Taillefer R, Robidoux A, Lambert R, Turpin S, Laperrière J. 99mTc-MIBI prone scintimammography to detect primary breast cancer and axillary lymph node involvement. $\mathrm{J} \mathrm{Nucl}$ Med 1995;36:1758-1765.

30. Villanueva-Meyer J, Leonhard MH, Briscoe E, et al. Mammoscintigraphy with Tc-99m sestamibi in suspected breast cancer. J Nucl Med 1996;37:926-930.

31. Tiling R, Kress K, Pechmann M, Pfluger T, Knesewitsch P, Tatsch K, Hahn K. integrated diagnosis of breast tumours: semiquantitative $99 \mathrm{~m}$ Tc-MIBI imaging versus dynamic MRI [abstract]. J Nucl Med 1995;35:51.

32. Burak Z, Argon M, Memis A, et al. Evaluation of palpable breast masses with Tc-99m MIBI: a comparative study with mammography and ultrasonography. Nucl Med Commun 1994;15:604-612.

33. Lee V, Sax EJ, McAneny DB, Pollack S, Blanchard RA, Beazley RM, Kavanah MT, Ward RJ. A complementary role for thallium-201 scintigraphy with mammography in the diagnosis of breast cancer. J Nucl Med 1993;34:2095-2100. 
34. Waxman AD, Ramanna L, Memsic LD, Foster CE, Silberman AW, Gleischmann SH, Brenner RJ, Brachman MB, Kuhar CJ, Yadegar J. Thallium scintigraphy in the evaluation of mass abnormalities of the breast. J Nucl Med 1993;34:18-23.

35. Cimitan M, Volpe R, Candiani E, et al. The use of Tl-201 in the preoperative detection of breast cancer: an adjunct to mammography and ultrasonography. Eur $J$ Nucl Med 1995;22:1110-1117.

36. Mansi L, Rambaldi PF, Procaccini E, et al. Scintimammography with Tc-99m tetrofosmin in the diagnosis of breast cancer and lymph node metastases. Eur J Nucl Med 1996;23: 932-939.

37. Piccolo S, Lastoria S, Mainolfi C, Muto P, Bazzicalupo L, Salvatore M. Tc-99m MDP scintimammography to image primary breast cancer. $J$ Nucl Med 1995;36:718-724.

38. Ell PJ. Keeping abreast of time. Eur J Nucl Med 1995;22: 967-969.

39. Sluyser M, Hoefnagel CA. Breast carcinomas detected by thallium-201 scintigraphy. Cancer Lett 1988;40:161-168.

40. Rijks LJ, Bakker PJ, van Tienhoven G, et al. Imaging of estrogen receptors in primary and metastatic breast cancer patients with I-123 Z-MIVE. J Clin Oncol 1997;15:2536-2545.

41. Maublant JC, Zhang Z, Rapp M, Ollier M, Michelot J, Veyre A. In vitro uptake of technetium-99m teboroxime in carcinoma cell lines and normal cells: comparison with technetium99m sestamibi and thallium-201. J Nucl Med 1993;34: 1949-1952.

42. Chiu ML, Kronauge JF, Piwnica-Worms D. Effect of mitochondrial and plasma membrane potentials on accumulation of hexakis 2-methoxyisobutylisonitrile technetium in cultured mouse fibroblasts. J Nucl Med 1990;31:1646-1653.

43. Piwnica-Worms D, Chiu ML, Budding M, Kronauge JF, Kramer RA, Croop JM. Functional imaging of multidrug-resistant P-glycoprotein with an organotechnetium complex. Cancer Res 1993;53:977-984.

44. Bender H, Friedrich E, Zamora PO, Guhlke S, Biersack HJ. Effect of Induction of multi-drug resistance on accumulation of Tc-99m sestamibi in vitro. Anticancer Res. 1997;17:18331840.

45. Ciarmiello A, Del Vecchio S, Potena MI, et al. Technetium99m-sestamibi efflux and P-glycoprotein expression in human breast carcinoma [abstract]. J Nucl Med 1995;36(Suppl.): $129 \mathrm{P}$.

46. Maublant J, Songalede JA, Finat-Duclos F, Verrelle P, Veyre A, Younès A. Accumulation of $99 \mathrm{mTc}-\mathrm{MIBI}$ in cultured tumour cells decreases when multidrug resistance factor is overexpressed [abstract]. J Nucl Med 1994;35(Suppl.):219P.

47. Khalkhali I, Villanueva-meyer J, Edell SL, et al. Diagnostic accuracy of $99 \mathrm{~m}$ Tc-MIBI breast imaging in breast cancer detection [abstract]. J Nucl Med 1996;7:74P.

48. Kopans DB. The positive predictive value of mammography. AJR 1992;158:521-526.

49. Khalkhali I, Cutrone JA, Mena I, Diggles L, Khalkhali S, Venegas R, Klein S. The usefulness of scintimammography (SMM) in patients with dense breasts on mammogram [abstract]. J Nucl Med 1995;36:52.

50. Khalkhali I, Villanueva-Meyer J, Edell SL, et al. Impact of breast density on the diagnostic accuracy of 99mTc-MIBI breast imaging in the detection of breast cancer [abstract]. $J$ Nucl Med 1996;37:74P.

51. Donnegan WL. Evaluation of a palpable breast mass. $N$ Engl J Med 1992;327:937-942.

52. Simpson JF, Page DL. Prognostic value of histopathology in the breast. Semin Oncol 1992;19:254-262.

53. Waxman A. The role of Tc-99m MIBI in imaging breast cancers. Semin Nucl Med 1997;17:40-54.

54. Wagner RH, Karesh SM, Dillehay GL, Henkin RE. Accuracy of needle localization of scintigraphic abnormalities using a radio-directed biopsy system (RDBS) [abstract]. J Nucl Med 1997;38:22P.

55. Khalkhali I, Mishkin FS, Diggles LE, Klein SR. Radionuclide-guided stereotactic prebiopsy localization of nonpalpable breast lesions with normal mammograms. J Nucl Med 1997;38:1019-1022. 